\title{
Influence of immune activation and inflammatory response on cardiovascular risk associated with the human immunodeficiency virus
}

This article was published in the following Dove Press journal:

Vascular Health and Risk Management

6 January 2015

Number of times this article has been viewed

\author{
Luis M Beltrán' \\ Alfonso Rubio-Navarro ${ }^{2}$ \\ Juan Manuel Amaro- \\ Villalobos ${ }^{2}$ \\ Jesús Egido ${ }^{2-4}$ \\ Juan García-Puig' \\ Juan Antonio Moreno \\ 'Metabolic-Vascular Unit, Fundación \\ IdiPAZ-Hospital Universitario La Paz, \\ Madrid, Spain; ${ }^{2}$ Vascular, Renal, and \\ Diabetes Research Lab, IIS-Fundación \\ Jiménez Díaz, Madrid, Spain; ${ }^{3}$ Centro \\ de Investigación Biomédica en Red de \\ Diabetes y Enfermedades Metabólicas \\ Asociadas (CIBERDEM), Madrid, \\ Spain; ${ }^{4}$ Fundación Renal Iñigo Alvarez \\ de Toledo-Instituto Reina Sofía de \\ Investigaciones Nefrológicas (FRIAT- \\ IRSIN), Madrid, Spain
}

\begin{abstract}
Patients infected with the human immunodeficiency virus (HIV) have an increased cardiovascular risk. Although initially this increased risk was attributed to metabolic alterations associated with antiretroviral treatment, in recent years, the attention has been focused on the HIV disease itself. Inflammation, immune system activation, and endothelial dysfunction facilitated by HIV infection have been identified as key factors in the development and progression of atherosclerosis. In this review, we describe the epidemiology and pathogenesis of cardiovascular disease in patients with HIV infection and summarize the latest knowledge on the relationship between traditional and novel inflammatory, immune activation, and endothelial dysfunction biomarkers on the cardiovascular risk associated with HIV infection.
\end{abstract}

Keywords: HIV, cardiovascular disease, immune activation, inflammation, antiretroviral therapy

\section{Importance of cardiovascular disease in patients infected with the human immunodeficiency virus}

In regions with universal access to care and antiretroviral therapy (ART), the prognosis of patients infected with the human immunodeficiency virus (HIV) has improved substantially. ${ }^{1-4}$ In the last 2 decades, the incidence and mortality of acquired immunodeficiency syndrome (AIDS)-defining illnesses (associated with severe immunosuppression in advanced stages of HIV infection) have been dramatically reduced, whereas the role of non-AIDS comorbidities has risen. ${ }^{5,6}$ A marked decrease in overall mortality due to AIDS-defining causes has been observed, while the proportion of deaths from other causes has increased, including those caused by cardiovascular disease (CVD). ${ }^{6-9}$ Similarly, hospitalizations due to AIDS-defining illnesses have decreased in European and North American populations, while admissions for non-AIDS diseases and CVD have increased. ${ }^{10,11}$

Patients with HIV infection have higher atherosclerotic CVD rates than the general population. ${ }^{12}$ HIV patients experience more clinical cardiovascular events (coronary heart disease ${ }^{13-15}$ and peripheral artery disease $),{ }^{16}$ and subclinical cardiovascular damage (elevation of intima-media thickness [IMT],${ }^{17}$ coronary calcification, ${ }^{18}$ abnormal anklebrachial index ${ }^{19}$ silent myocardial ischemia, ${ }^{20}$ or endothelial dysfunction) ${ }^{21}$ In addition, the incidence of ischemic stroke in the HIV-infected population is considerably high, particularly in young adults, although no studies have determined whether stroke risk is greater in this population. ${ }^{22,23}$

Besides atherosclerotic coronary heart disease, other cardiac abnormalities have been associated with HIV infection. ${ }^{24}$ Thus, in the pre-ART era, a high incidence of
Correspondence: Juan Antonio Moreno Vascular, Renal, and Diabetes Research Lab, IIS-Fundación Jiménez Díaz, Avda, Reyes Católicos 2, 28040 Madrid, Spain Tel +34 9I5 504800 ext 3I68 Email jamoreno@fjd.es 
dilated cardiomyopathy with left ventricular dysfunction related to viral myocarditis was reported, mainly during the AIDS stage. ${ }^{24}$ More recent studies, in settings with unrestricted access to ART, reported a low prevalence of dilated cardiomyopathy, but a high burden of subclinical myocardial disease (cardiac steatosis, myocardial fibrosis, and alterations in cardiac function) in HIV patients as compared to uninfected controls. ${ }^{25}$ Moreover, HIV patients may be at an increased risk of sudden arrhythmic death. The prevalence of prolonged corrected QT, a major risk for polymorphous ventricular tachycardia (Torsades de pointes) and sudden arrhythmic death, is also increased in HIV patients. ${ }^{26}$ In this regard, sudden cardiac death rate (due to atherosclerotic and/or arrhythmic causes) is 4.5-fold higher in HIV-infected patients than among those observed in the general population. ${ }^{27}$

On the other hand, the mean age of the HIV population is increasing due to the effectiveness of ART and increased life expectancy, favoring the development of age-associated comorbidities, many of which are related to CVD, such as type 2 diabetes mellitus (T2DM), hypertension (HT), and chronic kidney disease (CKD). In the Swiss HIV Cohort Study, ${ }^{28}$ which gathered patient data from 1990-2010, the proportion of patients older than 50 years increased from less than $5 \%$ to just over $30 \%$. It is expected that if this trend continues, in the next decade, $50 \%$ of patients in this cohort will be above 50 years.

In addition to chronological aging, it is believed that HIV patients experience accelerated biological aging, thus contributing to the early development of age-related comorbidities. ${ }^{29-31}$ Patients with HIV infection have a higher prevalence of noninfectious comorbidities commonly seen in the elderly (T2DM, CVD, osteoporosis, and CKD). ${ }^{32-35} \mathrm{An}$ interesting case-control study in an Italian population found a prevalence of comorbidity in HIV patients equivalent to that observed in control individuals 10-15 years older. ${ }^{32}$ As seen in these studies, we are witnessing a change in the patterns of morbidity and mortality among the HIV-infected population, leading researchers to shift the focus to non-AIDS comorbidity, where CVD plays a central role.

\section{Etiopathogenesis of cardiovascular disease in patients with HIV infection}

The higher cardiovascular risk observed in patients with HIV infection is due to a combination of several determinants, including factors related to antiretroviral treatment, the inherent impact of the infection, a high prevalence of traditional cardiovascular risk factors among HIV-infected individuals, and the presence of other factors that occur more frequently in these patients: coinfection with hepatitis $\mathrm{C}$ virus (HCV), coinfection and the replication of herpes family viruses, or the development of CKD (Figure 1).

\section{Antiretroviral drugs}

Initially, the elevated cardiovascular risk observed in HIV patients was attributed to metabolic alterations associated with ART, due particularly to the effect of viral protease inhibitors (PI), whose introduction into clinical practice coincided with the first reported cases of ischemic heart disease in HIV patients. $^{36,37}$ This relationship between CVD and ART was subsequently confirmed in epidemiological studies. ${ }^{12}$ The most representative study, the Data Collection on Adverse Events of Anti-HIV Drugs Study (DAD Study), ${ }^{38}$ showed a significant increase in acute myocardial infarction (AMI) incidence upon exposure to ART, with an increased AMI risk of $26 \%$ after 6 years of treatment. The increased cardiovascular risk associated with ART has been attributed to deleterious metabolic effects of these drugs, which favor the development of hypercholesterolemia and hypertriglyceridemia, insulin resistance, and T2DM. ${ }^{39}$ These alterations may occur either independently or as part of other disorders, such as metabolic syndrome or lipodystrophy. To a greater or lesser extent, the appearance of these entities has been reported in patients treated with PI drugs, nucleoside/nucleotide analog reverse transcriptase inhibitors (NRTIs) and non-nucleoside/nucleotide reverse transcriptase inhibitors. These alterations depend on the type of drug administered, and drugs belonging to the same family may have different effects. While these adverse effects have decreased with the new generation of antiretroviral drugs, ${ }^{40}$ the initiation of ART is usually associated with increased plasma lipids (triglycerides and total cholesterol with elevations in low-density lipoprotein [LDL] cholesterol [LDL-C] and, to a lesser extent, high-density lipoprotein cholesterol [HDL-C]) which, in part, could also be related to the weight gain observed after starting ART. ${ }^{41}$

In addition to these metabolic effects, the use of some antiretroviral drugs may induce other proatherogenic effects. Studies conducted in vitro and in healthy volunteers have revealed that some antiretrovirals - mainly PIs, but also NRTIs - could impair endothelial function, and increase oxidative stress and inflammation, inducing the early onset of senescence markers in endothelial and mononuclear cells. ${ }^{42-45}$ However, the data of many clinical studies suggest that ART dampens inflammation, immune activation and endothelial dysfunction in HIV-infected patients, probably through the suppression of HIV replication, as we further discuss. 


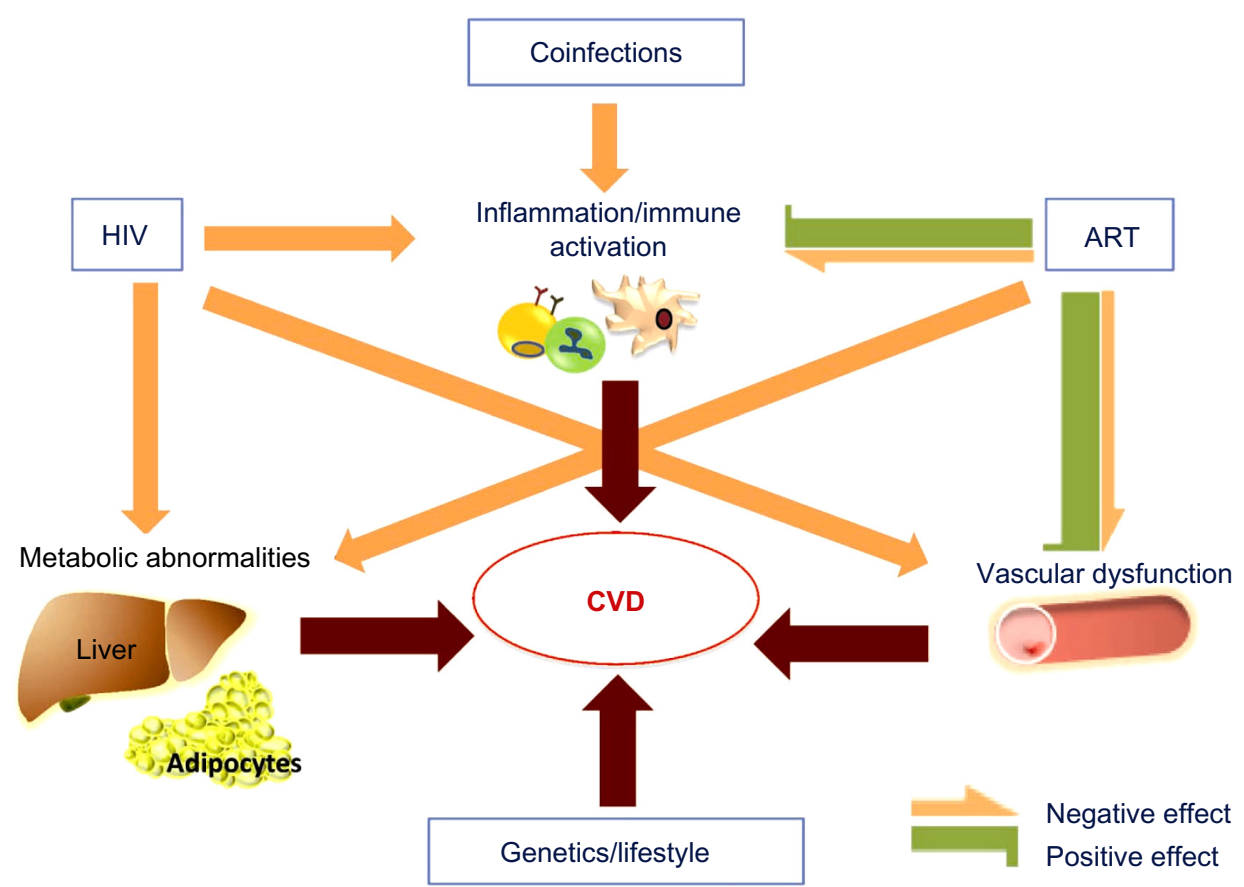

Figure I Determining factors of CVD in HIV-infected individuals.

Notes: In addition to lifestyle and individual predisposition, HIV-infected patients present other factors that determine CVD. HIV itself determines a state of persistent inflammation and immune activation, metabolic abnormalities, and vascular dysfunction. On the other hand, although some antiretroviral drugs may be associated with some deleterious alterations, ART has a positive net impact on inflammation, immune activation, and endothelial dysfunction that overcomes the possible deleterious effects associated with some drugs (note that the green lines are thicker than the orange ones). Finally, patients with HIV infection are frequently coinfected with HCV, CMV, or herpes viruses that may contribute to CVD by promoting chronic inflammation and immune activation.

Abbreviations: HIV, human immunodeficiency virus; ART, antiretroviral therapy; CVD, cardiovascular disease; HCV, hepatitis C virus; CMV, cytomegalovirus.

\section{HIV infection}

In recent years, the ART-dependent atherosclerosis hypothesis has been challenged. Evidence from experimental and observational studies, especially the findings of the Strategies for Management of Anti-Retroviral Therapy Study (SMART Study), ${ }^{46}$ have redirected attention from ART to the consequences of HIV infection itself. In this study, two different therapeutic strategies were compared. In the first group, ART was interrupted when a recovery of the immune system was achieved and CD4+ lymphocytes were above 350 cells $/ \mathrm{mL}$, whereas in the second group, ART was maintained continuously, regardless of CD4+ levels. Patients in whom the treatment was discontinued showed increased complications associated with immunosuppression and an increased risk of all-cause mortality. Moreover, patients assigned to discontinuous therapy exhibited an unexpected increase in cardiovascular outcomes in spite of less exposure to antiretroviral drugs. ${ }^{46}$ These results suggested that uncontrolled HIV infection might have a greater influence on CVD than ART.

HIV infection may increase cardiovascular risk by several mechanisms: 1) persistent inflammation and immune activation; 2) endothelial damage; 3 ) increased thrombotic activity; 4) higher oxidative stress; and 5) indirect metabolic disorders. HIV infection leads to the activation of several inflammatory pathways, causing the release of cytokines and endothelial adhesion molecule expression that facilitate adhesion and the transmigration of leukocytes. ${ }^{47}$ There is a close relationship between endothelial dysfunction and inflammation/immune activation. Various cytokines induce endothelial activation and alter its functionality. ${ }^{48}$ Additionally, HIV produces direct endothelial cell damage, increasing endothelial permeability, favoring apoptosis and increasing the expression of adhesion molecules (E-selectin, VCAM-1, and ICAM-1). ${ }^{49-54}$

HIV infection is also accompanied by immune activation, as determined by the elevation of several activation markers on monocytes/macrophages (sCD163, sCD14, and CD14+/ CD16+ monocyte expansion) and the increased proportion of activated CD8 T-lymphocytes human leukocyte antigen (HLA)-DR+CD38+. ${ }^{55-60}$ Monocytes/macrophages play a central role in the genesis and development of atherosclerosis. Thus, in atherosclerotic plaques, macrophages phagocyte modified lipoproteins, promote proinflammatory and chemotactic cytokine secretion, and mediate cholesterol efflux from the arterial wall. ${ }^{61} \mathrm{HIV}$ infection increases the proportion of CD14+/CD16+ monocytes, as it exhibits an activated 
phenotype with increased secretion of proinflammatory cytokines. ${ }^{58,59}$ Furthermore, HIV blocks the adenosine triphosphate-binding cassette transporter A1 (ABCA-1) pathway, suppressing reverse cholesterol transport from arterial wall macrophages to HDL particles, and favoring the accumulation of foam macrophages within atherosclerotic plaques. ${ }^{62}$

Inflammation and immune activation are also associated with increased thrombotic activity, with the elevation of biomarkers such as D-dimer (a fibrin degradation product that may be elevated in response to inflammatory stimuli and bacterial translocation), von Willebrand factor, and fibrinogen. ${ }^{63}$

HIV also induces oxidative stress, impairing the mechanisms of DNA repair and promoting the accumulation of oxidative lesions. ${ }^{64}$ Furthermore, HIV promotes atherogenesis through its metabolic effects, mainly decreasing HDL-C and apoA1, decreasing LDL particle clearance, as well as increasing triglycerides and very LDL-C. This pattern is associated with a high prevalence of proatherogenic small and dense LDL particles ${ }^{65-67}$ It has been proposed that circulating HDL particles in different proinflammatory conditions are functionally less active and are therefore less atheroprotective, reducing their ability to perform cholesterol efflux. ${ }^{68}$ However, this scenario has not been explored specifically in HIV infection.

Inflammation, immune activation, and prothrombotic state driven by HIV infection may participate not only in primary atherosclerosis, but also in occlusive complications after arterial revascularization procedures. It has been reported that HIV patients may have higher rates of stent restenosis and stent thrombosis after percutaneous coronary intervention. ${ }^{69-71}$ However, the results are not homogeneous and some studies report no differences in revascularization rates or major cardiac events after percutaneous coronary intervention in HIV-positive patients compared to age- and sex-matched HIV-negative subjects. ${ }^{72,73}$

\section{Traditional cardiovascular risk factors}

HIV patients show a high prevalence of certain traditional cardiovascular risk factors, such as smoking, dyslipidemia, and T2DM. ${ }^{12,74-76}$ The importance of these cardiovascular risk factors has been demonstrated in several cohort studies, highlighting a strong association between HIV and CVD, one that is even stronger than the link between ART and CVD. However, it is important to note that both ART and HIV infection may also induce dyslipidemia and diabetes.

\section{Lifestyle}

Smoking is very common in HIV patients, more so than in the general population; between $35 \%$ and $72 \%$ of HIV-infected individuals smoke depending on the population analyzed. ${ }^{77-81}$ Dietary habits also appear to be worse in HIV patients. In a case-control study that included 356 HIV-infected patients and 162 healthy volunteers, it was found that infected patients had significantly higher trans-, saturated-, and total fat and cholesterol consumption. ${ }^{82}$ One potential explanation for this difference is that without appropriate dietary control, many HIV patients have a greater caloric intake in order to compensate for lipoatrophy. Interestingly, in HIV patients that started ART, the incidence of dyslipidemia was significantly lower in those subjects who initiated a hypocaloric and low saturated fat diet as compared with patients who did not undergo a dietary intervention. ${ }^{41}$

\section{Metabolic cardiovascular risk factors}

Patients with HIV infection share the same predisposing factors for the development of dyslipidemia, diabetes, or metabolic syndrome as the general population. ${ }^{74}$ However, in these individuals, other factors coexist such as the HIV infection itself, ART, and/or HCV coinfection, which could explain the higher prevalence of abnormal carbohydrate and lipid metabolism observed in this population. In the DAD study, ${ }^{76}$ the prevalence of dyslipidemia at baseline was $45.9 \%$. It is expected that this prevalence would decrease with the use of lipid-lowering and antiretroviral drugs with a better metabolic profile. However, recent data from the Spanish cohort CoRIS ${ }^{81}$ showed that the prevalence remained elevated, as $27 \%$ of patients exhibited hypercholesterolemia, 36\% low HDL cholesterol, and 19\% hypertriglyceridemia. The frequency of abnormal carbohydrate metabolism has decreased in recent years, revealing a presence of diabetes of $17 \%$ in older cohorts, ${ }^{76}$ although a recent analysis found only $2.9 \%$ of the cohort to be diabetic. ${ }^{81}$ Patients with HIV infection also have a high prevalence of metabolic syndrome, around $25 \% .{ }^{81,83,84}$

\section{Hypertension}

The prevalence of HT in patients with HIV infection does not appear to be greater than in non-HIV individuals. ${ }^{73} \mathrm{~A}$ recent meta-analysis showed lower levels of systolic and diastolic blood pressure in HIV-infected patients compared to HIVnegative individuals. ${ }^{85}$ Interestingly, it has been hypothesized that in spite of normal brachial blood pressure, HIV patients may have higher arterial stiffness than healthy controls, ${ }^{86,87}$ emerging as an early marker of vascular damage related to HT; however, the data remain conflicting.$^{88}$ 


\section{Additional factors}

In addition to the HIV infection itself, other factors may be involved in the increased vascular risk in patients with HIV infection, such as the presence of chronic coinfections (HCV or herpes family viruses) and $\mathrm{CKD} .{ }^{40} \mathrm{HCV}$ infection promotes inflammation, platelet activation, endothelial dysfunction, and increased production of reactive oxygen species. ${ }^{89}$ In the general population, $\mathrm{HCV}$ infection has been associated with a higher prevalence of subclinical atherosclerosis ${ }^{90-92}$ and overt CVD. ${ }^{93-95}$ Similarly, in HIV patients, HCV coinfection has been associated with a higher frequency of atherosclerotic plaques (carotid or femoral) ${ }^{96}$ stroke, and AMI when compared to non-HCV coinfected patients. ${ }^{97,98}$

Latent infection with a virus of the herpes family has atherogenic effects ${ }^{99}$ and is associated with subclinical atherosclerosis. ${ }^{100,101}$ It has been hypothesized that herpes viruses may have more serious cardiovascular effects in HIV-infected patients, contributing to immune activation and inflammation. Cytomegalovirus (CMV) infection has been associated with atherosclerosis in HIV-infected patients. CMV-specific T-cell responses and CMV immunoglobulin G levels have been associated with increased carotid atherosclerosis. ${ }^{102,103}$ Moreover, other herpes viruses have been implicated. A case-control study that evaluated the association between subclinical coronary atherosclerosis and markers of CMV, herpes simplex virus 1 and 2 , and human herpes virus type 8 in HIV patients, showed that herpes simplex virus 2 was independently associated with the presence of subclinical coronary atherosclerosis, supporting the proatherogenic role of the herpes virus in this population. ${ }^{104}$

Finally, CKD is more frequent in HIV patients, and this factor is widely associated with CVD. ${ }^{105}$ This higher prevalence of renal disease can be explained by several factors, including a direct effect of HIV, the potential nephrotoxicity of some antiretroviral agents, the presence of traditional cardiovascular risk factors such as diabetes, and the development of atherosclerosis, which is bidirectionally associated with CKD. ${ }^{106}$ It is important to note that although some antiretroviral drugs may cause renal toxicity, many studies have shown that ART slows the decline of the estimated glomerular filtration rate, probably related to the effect of HIV viral suppression on glomerular function. ${ }^{107-109}$

\section{Inflammation, immune activation, and endothelial dysfunction in patients with HIV infection}

Multiple biomarkers of inflammation, immune activation, and endothelial dysfunction associated with CVD in the general population have been studied in HIV patients (Table 1). Numerous inflammatory mediators and adhesion molecules are elevated in the HIV population, including high-sensitive C-reactive protein (hsCRP), interleukin (IL)-6, soluble receptors of tumor necrosis factor (STNFR), soluble vascular cell adhesion molecule-1 (sVCAM-1), soluble intercellular adhesion molecule-1 (sICAM-1), or asymmetric dimethylarginine (ADMA). ${ }^{110-114}$ Some of these biomarkers have been associated with the presence of subclinical vascular disease and/or cardiovascular events in HIV-infected patients. Thus, hsCRP predicts the risk of CVD and all-cause mortality in the HIV population. ${ }^{115,116}$ High levels of IL-6 are also associated with an increased risk of death from any cause and cardiovascular events. ${ }^{116-118}$ Moreover, sTNFR has been associated with nonAIDS-defining morbid events during ART, including CVD. ${ }^{119}$ In HIV patients, the levels of sVCAM-1 have been associated with carotid IMT and carotid plaques, ${ }^{120,121}$ whereas ADMA levels have been related with coronary calcium score, all of which are surrogate markers of atherosclerosis. ${ }^{122}$

Immune activation markers are also elevated in the HIV population. Soluble markers such as sCD163 and sCD14, and the proportion of activated subsets of monocytes (CD14+/ CD16+) and CD8 T-cells (HLA-DR+CD38+), are increased in HIV patients. ${ }^{56-60,123,124}$ Our group has recently reported that HIV patients also have lower levels of soluble tumor necrosis factor-like weak inducer of apoptosis (sTWEAK), a multifunctional cytokine involved in various atherogenic processes through its interaction with Fn14 and CD163. ${ }^{124}$ sCD163 levels have been associated with the presence of subclinical atherosclerosis in patients with HIV infection. In 102 young HIV-infected men who were asymptomatic and had a low or undetectable viral load, sCD163 levels were independently associated with the percentage of noncalcified coronary plaques in both the overall analysis and in the 69 patients with undetectable viral RNA. ${ }^{125}$ These results were replicated in a study with $60 \mathrm{HIV}$-infected women that showed higher levels of sCD163 in those with noncalcified coronary plaques. ${ }^{126}$ Furthermore, in a similar scenario, sCD163 levels correlated positively with inflammation, as measured by aortic positron emission tomography. ${ }^{127}$ In both cases, neither the presence of coronary plaques nor vascular inflammation was associated with other biomarkers of CVD, such as hsCRP or D-dimer. sCD14 levels and CD14+/ CD16+ monocytes have also been associated with coronary artery calcium score. ${ }^{128,129}$ These results suggest that monocyte-macrophage activation could play a central role in both coronary and aortic atherosclerosis in HIV patients on effective ART, independently of classical inflammatory 
Table I Biomarkers of inflammation, immune activation, and endothelial dysfunction associated with CVD in the general population and performance in HIV-infected patients

\begin{tabular}{|c|c|c|c|c|}
\hline & $\begin{array}{l}\text { Association with CVD } \\
\text { in non-HIV patients }\end{array}$ & $\begin{array}{l}\text { Effect of } \\
\text { HIV* }\end{array}$ & $\begin{array}{l}\text { Effect of } \\
\text { ART }^{* *}\end{array}$ & $\begin{array}{l}\text { Association with CVD in HIV-infected } \\
\text { patients }\end{array}$ \\
\hline \multicolumn{5}{|l|}{ Inflammation } \\
\hline hsCRP & $\begin{array}{l}\uparrow \uparrow \text { in CVD patients and predicts } \\
\text { incident CVD } \\
164-167\end{array}$ & $\uparrow \uparrow 110$ & $\downarrow \downarrow \downarrow 124,130$ & $\mathrm{CVD}^{115,116}$ (not seen in Ford et $\mathrm{a}^{168}$ ) \\
\hline IL-6 & $\begin{array}{l}\uparrow \uparrow \text { in CVD patients and predicts } \\
\text { incident CVD }\end{array}$ & $\uparrow \uparrow 110$ & $\downarrow \downarrow^{|3|}$ & $C V D^{116-118}$ \\
\hline sTNFR & $\begin{array}{l}\uparrow \uparrow \text { in } \mathrm{LVH}^{173} \\
\text { Predicts } \mathrm{HF} \text { in } \mathrm{CAD} \mathrm{D}^{174-176}\end{array}$ & $\uparrow \uparrow 113,124$ & $\downarrow \downarrow \mid 24,131$ & $\begin{array}{l}\text { Subclinical atherosclerosis (IMT) })^{113,120} \\
\text { CVD }\end{array}$ \\
\hline \multicolumn{5}{|l|}{ Monocyte activation } \\
\hline sCDI63 & $\begin{array}{l}\uparrow \uparrow \text { in CAD, PAD, subclinical } \\
\text { atherosclerosis }^{177-179}\end{array}$ & $\uparrow \uparrow 58,59,123,124$ & $\downarrow \downarrow 123,124$ & $\begin{array}{l}\text { Subclinical atherosclerosis }(\mathrm{CoP})^{125,126} \\
\text { (not seen for IMT in Longenecker et al }{ }^{120} \text { ) } \\
\text { No prediction of first AMI' }{ }^{18, a}\end{array}$ \\
\hline sCDI4 & $\begin{array}{l}\text { Associated with subclinical } \\
\text { atherosclerosis and incident CVD }\end{array}$ & $\uparrow \uparrow 58-60$ & $\rightleftarrows^{137,138}$ & $\begin{array}{l}\text { Subclinical atherosclerosis (CAC, }{ }^{128} \mathrm{IMT}^{182} \text { ) } \\
\text { (not seen for IMT in Longenecker et al }{ }^{120} \text { ) }\end{array}$ \\
\hline CDI4+/CDI6+ expansion & $\begin{array}{l}\text { Associated with incident } \\
\text { CVD } \\
\text { et al }{ }^{183-185} \text { and } \text { Berg et a } \text { al }^{187} \text { ) }\end{array}$ & $\uparrow \uparrow 58,59$ & $\downarrow \downarrow^{123,136, \mathrm{~b}}$ & $\begin{array}{l}\text { Subclinical atherosclerosis }(C A C)^{129} \\
\text { (no association with IMT in Barbour et al| }{ }^{188} \text { ) }\end{array}$ \\
\hline \multicolumn{5}{|l|}{ Endothelial disturbances } \\
\hline sVCAM-I & $\begin{array}{l}\uparrow \uparrow \text { in CVD patients and predicts } \\
\text { incident CVD }\end{array}$ & $\uparrow \uparrow ! 11-113$ & $\downarrow \downarrow \downarrow 130-133$ & $\begin{array}{l}\text { Subclinical atherosclerosis (IMT, CaP }{ }^{|20,| 2 \mid} \text { ) } \\
\text { (not seen in Hileman et al }{ }^{|9|} \text { ) }\end{array}$ \\
\hline sICAM-I & $\begin{array}{l}\uparrow \uparrow \text { in CVD patients and predicts } \\
\text { incident CVD } \\
165,189-190\end{array}$ & $\uparrow \uparrow ॥ 11-113$ & $\downarrow \downarrow 130-133$ & No association with IMT in Hileman et al ${ }^{191}$ \\
\hline ADMA & $\begin{array}{l}\uparrow \uparrow \text { in CVD patients and predicts } \\
\text { incident CVD } \\
\text { 192,193 }\end{array}$ & $\uparrow \uparrow 114,124$ & $\begin{array}{l}\downarrow \downarrow^{134,135} \\
\text { (not seen in } \\
\text { Beltrán et } \mathrm{al}^{124} \text { ) }\end{array}$ & $\begin{array}{l}\text { Subclinical atherosclerosis }\left(\mathrm{CAC}^{122}\right) \\
\mathrm{PAH}^{194}\end{array}$ \\
\hline STWEAK & $\begin{array}{l}\downarrow \downarrow \text { in CVD patients } \\
\text { Low levels predict CV outcomes in } \\
\text { PAD, HF, and CKD patients }{ }^{197-199}\end{array}$ & $\downarrow \downarrow \downarrow^{124}$ & $\rightleftarrows^{124}$ & Not known \\
\hline
\end{tabular}

Notes: *Comparison of HIV-infected patients versus non-HIV-infected controls. **Comparison of HIV-infected patients prior to and after initiating ART. ${ }^{\text {a Nested case- }}$ control study. ${ }^{\circ H I V-i n f e c t e d ~ p a t i e n t s ~ r e c e i v i n g ~ A R T ~ p r e s e n t e d ~ w i t h ~ a ~ l o w e r ~ p r o p o r t i o n ~ o f ~ C D I 6+~ m o n o c y t e s ; ~ n o ~ c o m p a r i s o n ~ p r i o r ~ t o ~ v e r s u s ~ a f t e r ~ A R T . ~}$

Abbreviations: CVD, cardiovascular disease; HIV, human immunodeficiency virus; hsCRP, high sensitivity C-reactive protein; IL, interleukin; sTNFR, soluble receptors of tumor necrosis factor; LVH, left ventricular hypertrophy; HF, heart failure; IMT, intima-media thickness; CAD, coronary artery disease; PAD, peripheral artery disease; CoP, coronary plaques; AMI, acute myocardial infarction; CAC, coronary artery calcium; sVCAM-I, soluble vascular cell adhesion molecule-I; CaP, carotid plaques; sICAM-I, soluble intercellular adhesion molecule-I; ADMA, asymmetric dimethylarginine; PAH, pulmonary arterial hypertension; sTWEAK, soluble tumor necrosis factor-like weak inducer of apoptosis; CV, cardiovascular; CKD, chronic kidney disease; ART, antiretroviral therapy.

biomarkers. In apparent contrast to these results, a study of $60 \mathrm{HIV}$-infected patients receiving ART with controlled viral replication found no association between carotid IMT and plaques with sCD14, sCD163, or proinflammatory monocyte subsets. However, the IMT was correlated with concentrations of fibrinogen and sTNFR-I, and subjects with carotid plaques had higher levels of SVCAM-1 and a higher percentage of CD38+HLA-DR+ CD8 T-cells. ${ }^{120}$ These results are not necessarily contradictory and may reflect the specific role of different immune responses in the genesis of different atherosclerotic lesions. Supporting this hypothesis, it has been recently reported that in HIVtreated patients, $\mathrm{SCD} 14$ was independently associated with coronary artery calcium, while T-cell activation and systemic inflammation biomarkers, but not sCD14, correlated with carotid IMT. ${ }^{128}$ To clarify this issue, more studies are needed to assess the relationship of these biomarkers with the incidence of different atherosclerotic lesions in different vascular territories.

\section{Role of ART in the control of inflammation, endothelial dysfunction, and immune activation}

Contrary to the initial perception, a number of data support the notion that ART has a net protective effect on CVD in HIV patients. ${ }^{46}$ It is hypothesized that this effect is mediated by ART's ability to reduce inflammation, immune activation, and endothelial dysfunction by suppressing HIV replication (Table 1).

It has been reported that ART reduces inflammation and endothelial dysfunction biomarkers. ${ }^{130-135} \mathrm{~A}$ decrease in sVCAM-1, sICAM-1 and hsCRP was observed in 115 HIV-infected patients after 2 months and 14 months of antiretroviral treatment. ${ }^{117}$ In a further study, sTNFR-I, 
sTNFR-II, sVCAM-1, sICAM-1, and IL-6 plasma levels were significantly decreased after 24 weeks and 96 weeks of ART. ${ }^{131}$ Additionally, ADMA levels also seem to be reduced after successful ART with suppression of viral replication. ${ }^{134,135}$

A number of studies have also shown that immune activation decreases after ART. Data from two case-control studies suggest that sCD163 plasma levels decrease after ART. ${ }^{123,124}$ Moreover, ART-treated patients have a lower proportion of proinflammatory CD14+/CD16+ monocytes than patients who never received ART or those who discontinued this therapy. ${ }^{123,136}$ However, a reduction of sCD14 levels with ART has not been observed with similar concentrations before and after receiving treatment. ${ }^{137,138}$

It is important to note that even in individuals with spontaneously suppressed viremia, the so-called "controllers", ART reduced immune activation markers, specifically T-cell activation, and provoked a higher reduction of viremia. ${ }^{139}$ These patients showed higher subclinical CVD burden (coronary plaques or increased carotid IMT) than healthy individuals, in spite of maintaining suppressed viremia. ${ }^{140,141}$ Pereyra et $\mathrm{al}^{141}$ showed that controller HIV patients had a similar coronary disease burden as HIV patients on ART who exhibited suppressed viremia. In the study, controller HIV patients showed higher levels of sCD163, but no significant differences were observed in hsCRP plasma levels. ${ }^{141}$ These data support the key role of monocytes/macrophages in HIV-associated coronary atherosclerosis and the importance of ART in the reduction of activation of these cells, even in low viral replication situations.

However, it is important to note that ART did not completely reverse inflammation, immune activation, and endothelial dysfunction in HIV patients. In a study involving 781 patients from the SMART study and 8,500 HIV-seronegative control subjects from two large population-based studies (Multi-Ethnic Study of Atherosclerosis [MESA] study and Coronary Artery Development in Young Adults [CARDIA] study), the HIV patients had higher concentrations of hsCRP, IL-6, D-dimer, and C cystatin as compared with uninfected subjects, even when viral replication was suppressed with ART. ${ }^{110}$ Similar results were observed in a small case-control study, where ART reduced the concentrations of sVCAM-1, hsCRP, and sTNFR-II, although they remained elevated when compared with healthy subjects in spite of viral suppression. ${ }^{124}$ Also, sCD163 plasma levels decreased with ART but remained elevated as compared to healthy controls. ${ }^{123,124}$

Altogether, these results support the claim that ART reduces immune activation, inflammation, and endothelial activation, explaining the favorable net effect on cardiovascular risk, in spite of the deleterious metabolic effects. Therefore, ART is a key factor in preventing CVD in patients with HIV. However, in spite of ART, these patients maintain a persistent state of immune activation, inflammation, and endothelial activation that could justify the increased frequency of CVD observed in HIV patients, even with stable suppression of viral replication.

\section{Factors potentially involved in persistent inflammation and immune activation in HIV patients}

Several factors could explain the persistent state of immune activation, inflammation, and endothelial activation in spite of the suppression of viral replication after ART (Figure 2).

\section{Homeostatic drive and time to ART initiation}

Sustained viral replication may promote an immune/ inflammatory response that cannot be reversed after a certain point. Therefore, starting ART before reaching this immune/ inflammatory set point may prevent the state of persistent inflammation and immune activation. Supporting this hypothesis, the results of several studies have demonstrated that starting ART with low CD4 counts and/or a lowest CD4 nadir was associated with worse immunologic outcomes, even if patients achieved effective viral suppression. ${ }^{142-144}$ Treating HIV infection in the acute phase significantly reduces the proportion of activated CD38+HLA-DR+ CD8 T-cells when compared to nontreated patients. ${ }^{145,146}$ In the Options Project, ${ }^{147}$ patients who started ART in the first 6 months after infection had a lower proportion of activated CD8 T-cells than those who initiated treatment 2 years or more after the infection. In another interesting study, Burdo et al ${ }^{123}$ showed that patients with chronic HIV infection experienced a decrease of sCD163 levels after 3 months of ART; however, the sCD163 plasma concentration remained elevated as compared with controls. By contrast, in patients with early HIV infection ( $<1$ year postinfection), the sCD163 levels at 3 months of treatment were similar to those of controls. ${ }^{123}$ All together, these studies suggest that early ART could result in the decreased activation of CD8 T-cells and monocytes-macrophages, and they support the hypothesis that the activation of these cells could be reversed to normal levels with early ART.

\section{Residual viral replication}

Despite receiving effective ART, HIV patients may have residual viral replication below the detection limits of the 


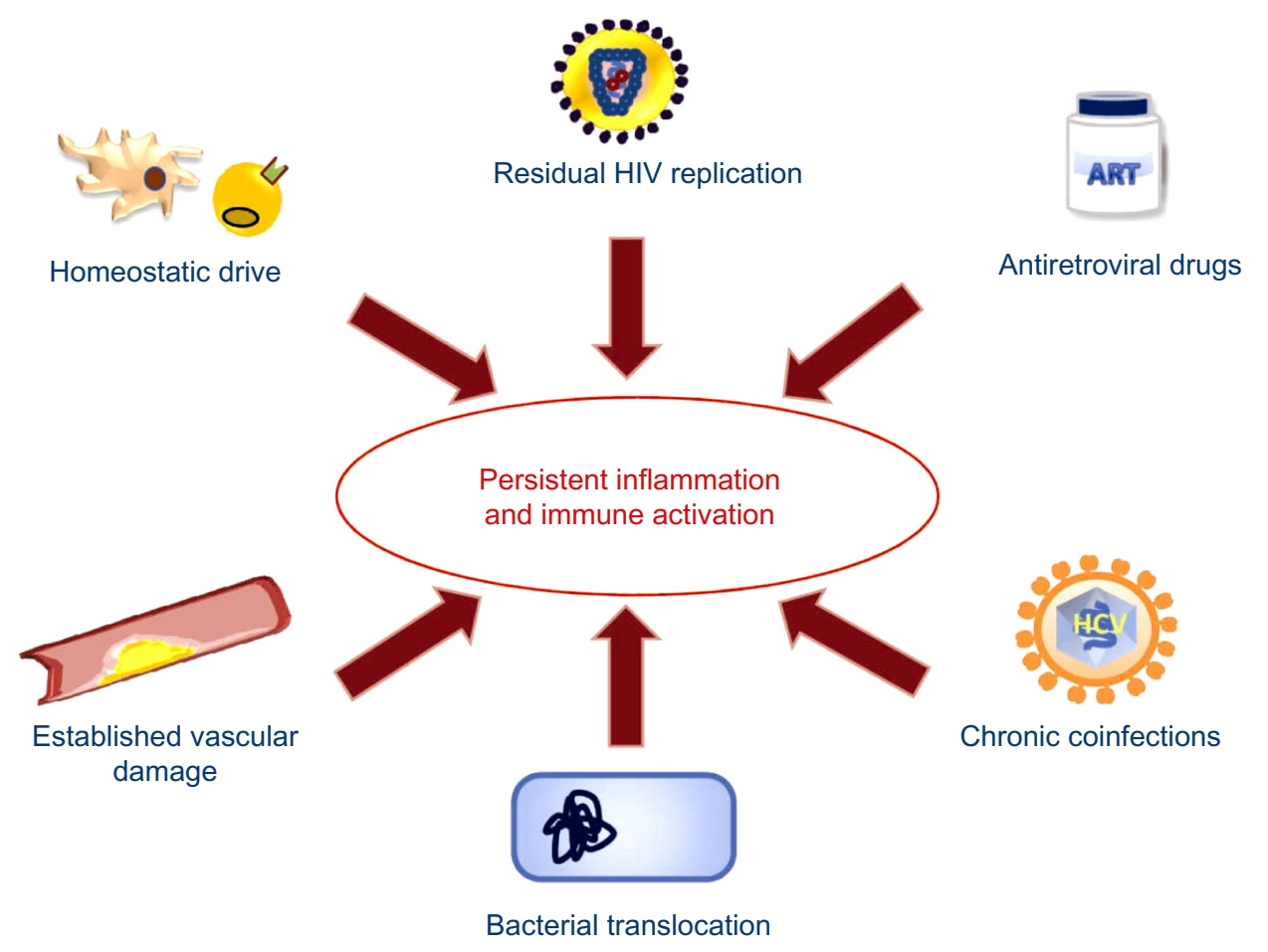

Figure 2 Factors implicated in persistent inflammation and immune activation in HIV patients.

Notes: HIV-infected patients have a persistent state of inflammation and immune activation in spite of the suppression of HIV replication via ART. Various factors might be implicated: I) homeostatic drive: after reaching an immune/inflammatory set point, the immunological and inflammatory response persist in spite of eliminating the initial stimulus; 2) residual nondetected HIV replication; 3) proinflammatory effects of certain antiretroviral drugs; 4) translocation of bacterial products through damaged intestinal mucosa; 5) coexistence of chronic HCV or herpes virus infection, common in the HIV population; and 6) established vascular lesions.

Abbreviations: HIV, human immunodeficiency syndrome; ART, antiretroviral therapy; HCV, hepatitis C virus.

techniques commonly used, and/or they may have episodes of transient viral replication. It has been hypothesized that adding an additional antiretroviral drug could control this residual viral replication and reduce inflammation and immune activation, although the data are controversial. The results on the effect of ART intensification with maraviroc or raltegravir are contradictory, and the effect on the reduction of the inflammatory response, in any case, is modest. ${ }^{148-152}$

\section{ART-dependent effects}

Some antiretroviral drugs can induce endothelial dysfunction and oxidative stress and promote an inflammatory response. Drugs such as ritonavir, indinavir, lopinavir, zidovudine, and abacavir have been associated with these deleterious effects. ${ }^{42-45}$ It has been suggested that other antiretroviral drugs, such as raltegravir, may have an additional beneficial effect on these processes, independently of the suppression of viral replication. Some studies have shown that substituting a PI or non-nucleoside/nucleotide reverse transcriptase inhibitors with raltegravir reduces the levels of circulating inflammatory markers such as IL-6, hsCRP, or D-dimer. ${ }^{153-155}$

\section{Coinfections}

Chronic coinfections with HCV or herpes viruses, very common in the HIV population, might activate inflammatory and immunological mechanisms, although HIV viral replication is suppressed.

\section{Bacterial translocation}

HIV causes damage in the intestinal mucosa, favoring the translocation of bacterial products that stimulate immune activation. ${ }^{156-158}$ During acute infection phases, HIV severely damages the lymphoid tissue associated with the intestinal mucosa, with a massive depletion of T-cell lymphocytes. In patients with controlled chronic HIV infection, this lymphoid tissue cannot fully recover, and a predisposition to bacterial translocation persists in spite of ART. ${ }^{159,160}$

\section{Established atherosclerosis}

Atherosclerosis is, by itself, a process that is accompanied by persistent inflammation and immune activation. ${ }^{161}$ The development of atherosclerotic lesions prior to the start of the suppressive ART could be partially responsible for the persistent elevation of inflammation and immune activation biomarkers (intraplaque foam cells and endothelial dysfunction). In this 
regard, the use of rosuvastatin in patients receiving ART has revealed reduced circulating levels of $\mathrm{sCD} 14$ and decreased CD14+/CD16+ monocytes, but it did not affect systemic inflammatory biomarkers. ${ }^{162,163}$

\section{Conclusion}

Patients with HIV infection are at increased cardiovascular risk due to the HIV infection itself, and due to other factors such as ART-associated metabolic abnormalities, lifestyle, or the coexistence of chronic infections. ART was initially proposed as the causal factor for CVD in these patients; however, there is growing evidence supporting a net beneficial effect on CVD risk, presumably through the control of viral replication and the subsequent reduction of inflammation and immune activation. Nevertheless, in spite of optimal treatment, HIV patients maintain a state of persistent inflammation and immune activation that facilitates the development of CVD. In this regard, strategies to control these processes, in addition to ART and the treatment of traditional cardiovascular risk factors, may be useful in CVD prevention for HIV patients.

\section{Acknowledgments}

We thank Isabel Martin (Hospital Quirón San Camilo, Madrid) for her assistance in the design and preparation of the figures. We thank Oliver Shawn (Instituto de Investigaciones Sanitarias Fundación Jiménez Díaz [IIS-FJD]) for his editorial assistance. This work has been supported by grants from FIS (Programa Miguel Servet: CP10/00479, PI13/00802 and PI14/00883) and Spanish Society of Nephrology to Juan Antonio Moreno.

\section{Disclosure}

The authors report no conflicts of interest in this work.

\section{References}

1. Palella FJ, Delaney KM, Moorman AC, et al. Declining morbidity and mortality among patients with advanced human immunodeficiency virus infection. HIV Outpatient Study Investigators. $N$ Engl J Med. 1998;338(13):853-860.

2. Mocroft A, Ledergerber B, Katlama C, et al; EuroSIDA study group. Decline in the AIDS and death rates in the EuroSIDA study: an observational study. Lancet. 2003;362(9377):22-29.

3. Lima VD, Hogg RS, Harrigan PR, et al. Continued improvement in survival among HIV-infected individuals with newer forms of highly active antiretroviral therapy. AIDS. 2007;21(6):685-692.

4. Luz PM, Bruyand M, Ribeiro S, et al; IPEC/FIOCRUZ Cohort and the Aquitaine ANRS C03 Study Group. AIDS and non-AIDS severe morbidity associated with hospitalizations among HIV-infected patients in two regions with universal access to care and antiretroviral therapy, France and Brazil, 2000-2008: hospital-based cohort studies. BMC Infect Dis. 2014; 14:278.

5. Palella FJ Jr, Baker RK, Moorman AC, et al; HIV Outpatient Study Investigators. Mortality in the highly active antiretroviral therapy era: changing causes of death and disease in the HIV outpatient study. J Acquir Immune Defic Syndr. 2006;43(1):27-34.
6. Crum NF, Riffenburgh RH, Wegner S, et al; Triservice AIDS Clinical Consortium. Comparisons of causes of death and mortality rates among HIV-infected persons: analysis of the pre-, early, and late HAART (highly active antiretroviral therapy) eras. JAcquir Immune Defic Syndr. 2006;41(2):194-200.

7. Morlat P, Roussillon C, Henard S, et al; ANRS EN20 Mortalité 2010 Study Group. Causes of death among HIV-infected patients in France in 2010 (national survey): trends since 2000. AIDS. 2014;28(8): 1181-1191.

8. French AL, Gawel SH, Hershow R, et al. Trends in mortality and causes of death among women with HIV in the United States: a 10-year study. J Acquir Immune Defic Syndr. 2009;51(4):399-406.

9. Mocroft A, Reiss P, Gasiorowski J, et al; EuroSIDA Study Group. Serious fatal and nonfatal non-AIDS-defining illnesses in Europe. J Acquir Immune Defic Syndr. 2010;55(2):262-270.

10. Berry SA, Fleishman JA, Moore RD, Gebo KA; HIV ResearchNetwork. Trends in reasons for hospitalization in a multisite United States cohort of persons living with HIV, 2001-2008. J Acquir Immune Defic Syndr. 2012;59(4):368-375.

11. Engsig FN, Hansen AB, Gerstoft J, Kronborg G, Larsen CS, Obel N. Inpatient admissions and outpatient visits in persons with and without HIV infection in Denmark, 1995-2007. AIDS. 2010;24(3):457-461.

12. Currier JS, Lundgren JD, Carr A, et al; Working Group 2. Epidemiological evidence for cardiovascular disease in HIV-infected patients and relationship to highly active antiretroviral therapy. Circulation. 2008;118(2):e29-e35.

13. Triant VA, Lee H, Hadigan C, Grinspoon SK. Increased acute myocardial infarction rates and cardiovascular risk factors among patients with human immunodeficiency virus disease. J Clin Endocrinol Metab. 2007;92(7):2506-2512.

14. Islam FM, Wu J, Jansson J, Wilson DP. Relative risk of cardiovascular disease among people living with HIV: a systematic review and metaanalysis. HIV Med. 2012;13(8):453-468.

15. Currier JS, Taylor A, Boyd F, et al. Coronary heart disease in HIV-infected individuals. J Acquir Immune Defic Syndr. 2003;33(4):506-512.

16. Palacios R, Alonso I, Hidalgo A, et al. Peripheral arterial disease in HIV patients older than 50 years of age. AIDS Res Hum Retroviruses. 2008;24(8):1043-1046.

17. Lorenz MW, Stephan C, Harmjanz A, et al. Both long-term HIV infection and highly active antiretroviral therapy are independent risk factors for early carotid atherosclerosis. Atherosclerosis. 2008;196(2): 720-726.

18. Kingsley LA, Cuervo-Rojas J, Muñoz A, et al. Subclinical coronary atherosclerosis, HIV infection and antiretroviral therapy: Multicenter AIDS Cohort Study. AIDS. 2008;22(13):1589-1599.

19. Periard D, Cavassini M, Taffé P, et al; Swiss HIV Cohort Study. High prevalence of peripheral arterial disease in HIV-infected persons. Clin Infect Dis. 2008;46(5):761-767.

20. Carr A, Grund B, Neuhaus J, et al; SMART Study Investigators. Asymptomatic myocardial ischaemia in HIV-infected adults. AIDS. 2008;22(2):257-267.

21. Solages A, Vita JA, Thornton DJ, et al. Endothelial function in HIVinfected persons. Clin Infect Dis. 2006;42(9):1325-1332.

22. Sen S, Rabinstein AA, Elkind MS, Powers WJ. Recent developments regarding human immunodeficiency virus infection and stroke. Cerebrovasc Dis. 2012;33(3):209-218.

23. Ovbiagele B, Nath A. Increasing incidence of ischemic stroke in patients with HIV infection. Neurology. 2011;76(5):444-450.

24. De Castro S, d'Amati G, Gallo P, et al. Frequency of development of acute global left ventricular dysfunction in human immunodeficiency virus infection. J Am Coll Cardiol. 1994;24(4):1018-1024.

25. Holloway CJ, Ntusi N, Suttie J, et al. Comprehensive cardiac magnetic resonance imaging and spectroscopy reveal a high burden of myocardial disease in HIV patients. Circulation. 2013;128(8):814-822.

26. Vallecillo G, Mojal S, Roquer A, et al. Risk of QTc prolongation in a cohort of opioid-dependent HIV-infected patients on methadone maintenance therapy. Clin Infect Dis. 2013;57(8):1189-1194. 
27. Moyers BS, Secemsky EA, Vittinghoff E, et al. Effect of left ventricular dysfunction and viral load on risk of sudden cardiac death in patients with human immunodeficiency virus. Am J Cardiol. 2014;113(7):1260-1265.

28. Hasse B, Ledergerber B, Furrer H, et al; Swiss HIV Cohort Study. Morbidity and aging in HIV-infected persons: the Swiss HIV cohort study. Clin Infect Dis. 2011;53(11):1130-1139.

29. Deeks SG, Phillips AN. HIV infection, antiretroviral treatment, ageing, and non-AIDS related morbidity. BMJ. 2009;338:a3172.

30. Deeks SG. HIV infection, inflammation, immunosenescence, and aging. Annu Rev Med. 2011;62:141-155.

31. Effros RB, Fletcher CV, Gebo K, et al. Aging and infectious diseases: workshop on HIV infection and aging: what is known and future research directions. Clin Infect Dis. 2008;47(4):542-553.

32. Guaraldi G, Orlando G, Zona S, et al. Premature age-related comorbidities among HIV-infected persons compared with the general population. Clin Infect Dis. 2011;53(11):1120-1126.

33. Kirk JB, Goetz MB. Human immunodeficiency virus in an aging population, a complication of success. JAm Geriatr Soc. 2009;57(11): 2129-2138.

34. Deeks SG, Phillips AN. HIV infection, antiretroviral treatment, ageing, and non-AIDS related morbidity. BMJ. 2009;338:a3172.

35. Goulet JL, Fultz SL, Rimland D, et al. Aging and infectious diseases: do patterns of comorbidity vary by HIV status, age, and HIV severity? Clin Infect Dis. 2007;45(12):1593-1601.

36. Henry K, Melroe H, Huebsch J, et al. Severe premature coronary artery disease with protease inhibitors. Lancet. 1998;351(9112):1328.

37. Gallet B, Pulik M, Genet P, Chedin P, Hiltgen M. Vascular complications associated with use of HIV protease inhibitors. Lancet. 1998; 351(9120):1958-1959.

38. Friis-Møller N, Sabin CA, Weber R, et al; Data Collection on Adverse Events of Anti-HIV Drugs (DAD) Study Group. Combination antiretroviral therapy and the risk of myocardial infarction. $N$ Engl $J$ Med. 2003;349(21):1993-2003.

39. Hadigan C, Meigs JB, Corcoran C, et al. Metabolic abnormalities and cardiovascular disease risk factors in adults with human immunodeficiency virus infection and lipodystrophy. Clin Infect Dis. 2001;32(1):130-139.

40. Hemkens LG, Bucher HC. HIV infection and cardiovascular disease. Eur Heart J. 2014;35(21):1373-1381.

41. Lazzaretti RK, Kuhmmer R, Sprinz E, Polanczyk CA, Ribeiro JP. Dietary intervention prevents dyslipidemia associated with highly active antiretroviral therapy in human immunodeficiency virus type 1-infected individuals: a randomized trial. J Am Coll Cardiol. 2012;59(11): 979-988.

42. Conklin B, Fu W, Lin P, Lundsen A, Yao Q, Chen C. HIV protease inhibitor ritonavir induces endothelial dysfunction in porcine arteries. J Surg Res. 2003;114:249.

43. Shankar SS, Dubé MP, Gorski JC, Klaunig JE, Steinberg HO. Indinavir impairs endothelial function in healthy HIV-negative men. Am Heart J. 2005;150(5):933.

44. Lagathu C, Eustace B, Prot M, et al. Some HIV antiretrovirals increase oxidative stress and alter chemokine, cytokine or adiponectin production in human adipocytes and macrophages. Antivir Ther. 2007;12(4): 489-500.

45. Lefèvre C, Auclair M, Boccara F, et al. Premature senescence of vascular cells is induced by HIV protease inhibitors: implication of prelamin A and reversion by statin. Arterioscler Thromb Vasc Biol. 2010;30(12): 2611-2620.

46. El-Sadr WM, Lundgren J, Neaton JD, et al; Strategies for Management of Antiretroviral Therapy (SMART) Study Group. CD4+ count-guided interruption of antiretroviral treatment. N Engl J Med. 2006;355(22): 2283-2296.

47. Fisher SD, MillerTL, Lipshultz SE. Impact of HIV and highly active antiretroviral therapy on leukocyte adhesion molecules, arterial inflammation, dyslipidemia, and atherosclerosis. Atherosclerosis. 2006; 185(1):1-11.

48. Mu H, Chai H, Lin PH, Yao Q, Chen C. Current update on HIVassociated vascular disease and endothelial dysfunction. World J Surg. 2007;31(4):632-643.
49. Eugenin EA, Morgello S, Klotman ME, et al. Human immunodeficiency virus (HIV) infects human arterial smooth muscle cells in vivo and in vitro: implications for the pathogenesis of HIV-mediated vascular disease. Am J Pathol. 2008;172(4):1100-1111.

50. Oshima T, Flores SC, Vaitaitis G, et al. HIV-1 Tat increases endothelial solute permeability through tyrosine kinase and mitogen-activated protein kinase-dependent pathways. AIDS. 2000;14(5):475-482.

51. Jia H, Lohr M, Jezequel S, et al. Cysteine-rich and basic domain HIV-1 Tat peptides inhibit angiogenesis and induce endothelial cell apoptosis. Biochem Biophys Res Commun. 2001;283(2):469-479.

52. Huang MB, Khan M, Garcia-Barrio M, Powell M, Bond VC. Apoptotic effects in primary human umbilical vein endothelial cell cultures caused by exposure to virion-associated and cell membrane-associated HIV-1 gp120. J Acquir Immune Defic Syndr. 2001;27(3):213-221.

53. Dhawan S, Puri RK, Kumar A, Duplan H, Masson JM, Aggarwal BB. Human immunodeficiency virus-1-tat protein induces the cell surface expression of endothelial leukocyte adhesion molecule-1, vascular cell adhesion molecule-1, and intercellular adhesion molecule-1 in human endothelial cells. Blood. 1997;90(4):1535-1544.

54. Ren Z, Yao Q, Chen C. HIV-1 envelope glycoprotein 120 increases intercellular adhesion molecule-1 expression by human endothelial cells. Lab Invest. 2002;82(3):245-255.

55. Sandler NG, Sereti I. Can early therapy reduce inflammation? Curr Opin HIV AIDS. 2014;9(1):72-79.

56. Liovat AS, Rey-Cuillé MA, Lécuroux C, et al. Acute plasma biomarkers of T cell activation set-point levels and of disease progression in HIV-1 infection. PLoS One. 2012;7(10):e46143.

57. Burdo TH, Soulas C, Orzechowski K, et al. Increased monocyte turnover from bone marrow correlates with severity of SIV encephalitis and CD163 levels in plasma. PLoS Pathog. 2010;6(4):e1000842.

58. Hearps AC, Maisa A, Cheng WJ, et al. HIV infection induces age-related changes to monocytes and innate immune activation in young men that persist despite combination antiretroviral therapy. AIDS. 2012;26(7): 843-853.

59. Martin GE, Gouillou M, Hearps AC, et al. Age-associated changes in monocyte and innate immune activation markers occur more rapidly in HIV infected women. PLoS One. 2013;8(1):e55279.

60. Armah KA, McGinnis K, Baker J, et al. HIV status, burden of comorbid disease, and biomarkers of inflammation, altered coagulation, and monocyte activation. Clin Infect Dis. 2012;55(1):126-136.

61. Crowe SM, Westhorpe CL, Mukhamedova N, Jaworowski A, Sviridov D, Bukrinsky M. The macrophage: the intersection between HIV infection and atherosclerosis. J Leukoc Biol. 2010;87(4):589-598.

62. Mujawar Z, Rose H, Morrow MP, et al. Human immunodeficiency virus impairs reverse cholesterol transport from macrophages. PLoS Biol. 2006;4(11):e365.

63. Funderburg NT. Markers of coagulation and inflammation often remain elevated in ART-treated HIV-infected patients. Curr Opin HIV AIDS. 2014;9(1):80-86

64. Aukrust P, Luna L, Ueland T, et al. Impaired base excision repair and accumulation of oxidative base lesions in CD4+ T cells of HIV-infected patients. Blood. 2005;105(12):4730-4735.

65. Grunfeld C, Pang M, Doerrler W, et al. Lipids, lipoproteins, triglyceride clearance, and cytokines in human immunodeficiency virus infection and the acquired immunodeficiency syndrome. J Clin Endocrinol Metab. 1992;74(5):1045-1052.

66. Rose H, Hoy J, Woolley I, et al. HIV infection and high density lipoprotein metabolism. Atherosclerosis. 2008;199(1):79-86.

67. Oh J, Hegele RA. HIV-associated dyslipidaemia: pathogenesis and treatment. Lancet Infect Dis. 2007;7(12):787-796.

68. Norata GD, Pirillo A, Catapano AL. HDLs, immunity, and atherosclerosis. Curr Opin Lipidol. 2011;22(5):410-416.

69. D'Ascenzo F, Cerrato E, Appleton D, et al; Percutaneous coronary intervention and surgical revascularization in HIV Database (PHD) Study Investigators. Prognostic indicators for recurrent thrombotic events in HIV-infected patients with acute coronary syndromes: use of registry data from 12 sites in Europe, South Africa and the United States. Thromb Res. 2014;134(3):558-564. 
70. Matetzky S, Domingo M, Kar S, et al. Acute myocardial infarction in human immunodeficiency virus-infected patients. Arch Intern Med. 2003;163(4):457-460.

71. Segev A, Cantor WJ, Strauss BH. Outcome of percutaneous coronary intervention in HIV-infected patients. Catheter Cardiovasc Interv. 2006;68(6):879-881.

72. Boccara F, Teiger E, Cohen A, et al. Percutaneous coronary intervention in HIV infected patients: immediate results and long term prognosis. Heart. 2006;92(4):543-544.

73. Badr S, Minha S, Kitabata H, et al. Safety and long-term outcomes after percutaneous coronary intervention in patients with human immunodeficiency virus. Catheter Cardiovasc Interv. Epub February 28, 2014.

74. Savès M, Chêne G, Ducimetière P, et al; French WHO MONICA Project and the APROCO (ANRS EP11) Study Group. Risk factors for coronary heart disease in patients treated for human immunodeficiency virus infection compared with the general population. Clin Infect Dis. 2003;37(2):292-298.

75. Brown TT, Cole SR, Li X, et al. Antiretroviral therapy and the prevalence and incidence of diabetes mellitus in the multicenter AIDS cohort study. Arch Intern Med. 2005;165(10):1179-1184.

76. Friis-Møller N, Weber R, Reiss P, et al; DAD study group. Cardiovascular disease risk factors in HIV patients - association with antiretroviral therapy. Results from the DAD study. AIDS. 2003;17(8): 1179-1193.

77. Smith CJ, Levy I, Sabin CA, Kaya E, Johnson MA, Lipman MC Cardiovascular disease risk factors and antiretroviral therapy in an HIV-positive UK population. HIV Med. 2004;5(2):88-92.

78. Santos J, Palacios R, González M, Ruiz J, Márquez M. Atherogenic lipid profile and cardiovascular risk factors in HIV-infected patients (Nétar Study). Int J STD AIDS. 2005;16(10):677-680.

79. Glass TR, Ungsedhapand C, Wolbers M, et al; Swiss HIV Cohort Study. Prevalence of risk factors for cardiovascular disease in HIVinfected patients over time: the Swiss HIV Cohort Study. HIV Med. 2006;7(6):404-410.

80. Kaplan RC, Kingsley LA, Sharrett AR, et al. Ten-year predicted coronary heart disease risk in HIV-infected men and women. Clin Infect Dis. 2007;45(8):1074-1081.

81. Masiá M, Pérez-Cachafeiro S, Leyes M, et al; Grupo de estudio de riesgo cardiovascular de CoRIS. [Cardiovascular risk in human immunodeficiency virus-infected patients in Spain. CoRIS cohort, 2011]. Enferm Infecc Microbiol Clin. 2012;30(9):517-527. Spanish.

82. Joy T, Keogh HM, Hadigan C, et al. Dietary fat intake and relationship to serum lipid levels in HIV-infected patients with metabolic abnormalities in the HAART era. AIDS. 2007;21(12):1591-1600.

83. Mondy K, Overton ET, Grubb J, et al. Metabolic syndrome in HIVinfected patients from an urban, midwestern US outpatient population. Clin Infect Dis. 2007;44(5):726-734.

84. Palacios R, Santos J, González M, Ruiz J, Márquez M. Incidence and prevalence of the metabolic syndrome in a cohort of naive HIV-infected patients: prospective analysis at 48 weeks of highly active antiretroviral therapy. Int J STD AIDS. 2007;18(3):184-187.

85. Dillon DG, Gurdasani D, Riha J, et al; African Partnership for Chronic Disease Research (APCDR). Association of HIV and ART with cardiometabolic traits in sub-Saharan Africa: a systematic review and meta-analysis. Int J Epidemiol. 2013;42(6):1754-1771.

86. Schillaci G, De Socio GV, Pucci G, et al. Aortic stiffness in untreated adult patients with human immunodeficiency virus infection. Hypertension. 2008;52(2):308-313.

87. Lekakis J, Ikonomidis I, Palios J, et al. Association of highly active antiretroviral therapy with increased arterial stiffness in patients infected with human immunodeficiency virus. Am J Hypertens. 2009;22(8): 828-834.

88. Echeverría P, Bonjoch A, Moltó J, et al. Pulse wave velocity as index of arterial stiffness in HIV-infected patients compared with a healthy population. J Acquir Immune Defic Syndr. 2014;65(1):50-56.

89. Adinolfi LE, Restivo L, Zampino R, et al. Chronic HCV infection is a risk of atherosclerosis. Role of $\mathrm{HCV}$ and $\mathrm{HCV}$-related steatosis. Atherosclerosis. 2012;221(2):496-502.
90. Ishizaka N, Ishizaka Y, Takahashi E, et al. Association between hepatitis $\mathrm{C}$ virus seropositivity, carotid-artery plaque, and intima-media thickening. Lancet. 2002;359(9301):133-135.

91. Alyan O, Kacmaz F, Ozdemir O, et al. Hepatitis C infection is associated with increased coronary artery atherosclerosis defined by modified Reardon severity score system. Circ J. 2008;72(12):1960-1965.

92. Vassalle C, Masini S, Bianchi F, Zucchelli GC. Evidence for association between hepatitis $\mathrm{C}$ virus seropositivity and coronary artery disease. Heart. 2004;90(5):565-566.

93. Lee $\mathrm{MH}$, Yang HI, Wang $\mathrm{CH}$, et al. Hepatitis $\mathrm{C}$ virus infection and increased risk of cerebrovascular disease. Stroke. 2010;41(12): 2894-2900.

94. Younossi ZM, Stepanova M, Nader F, Younossi Z, Elsheikh E. Associations of chronic hepatitis $\mathrm{C}$ with metabolic and cardiac outcomes. Aliment Pharmacol Ther. 2013;37(6):647-652.

95. Hsu YH, Muo CH, Liu CY, et al. Hepatitis C virus infection increases the risk of Developing peripheral arterial disease: a 9-year populationbased cohort study. J Hepatol. Epub September 25, 2014.

96. Sosner P, Wangermez M, Chagneau-Derrode C, Le Moal G, Silvain C. Atherosclerosis risk in HIV-infected patients: the influence of hepatitis C virus co-infection. Atherosclerosis. 2012;222(1):274-277.

97. Bedimo R, Westfall AO, Mugavero M, Drechsler H, Khanna N, Saag M. Hepatitis $\mathrm{C}$ virus coinfection and the risk of cardiovascular disease among HIV-infected patients. HIV Med. 2010;11(7):462-468.

98. Gillis J, Smieja M, Cescon A, et al; OHTN Cohort Study Group. Risk of cardiovascular disease associated with HCV and HBV coinfection among antiretroviral-treated HIV-infected individuals. Antivir Ther. 2014;19(3):309-317.

99. Sutherland MR, Raynor CM, Leenknegt H, Wright JF, Pryzdial EL. Coagulation initiated on herpesviruses. Proc Natl Acad Sci U S A. 1997;94(25):13510-13514.

100. Sun Y, Pei W, Wu Y, Jing Z, Zhang J, Wang G. Herpes simplex virus type 2 infection is a risk factor for hypertension. Hypertens Res. 2004;27(8):541-544.

101. Espinola-Klein C, Rupprecht HJ, Blankenberg S, et al; AtheroGene Investigators. Impact of infectious burden on extent and long-term prognosis of atherosclerosis. Circulation. 2002;105(1):15-21.

102. Hsue PY, Hunt PW, Sinclair E, et al. Increased carotid intima-media thickness in HIV patients is associated with increased cytomegalovirusspecific T-cell responses. AIDS. 2006;20(18):2275-2283.

103. Parrinello CM, Sinclair E, Landay AL, et al. Cytomegalovirus immunoglobulin $\mathrm{G}$ antibody is associated with subclinical carotid artery disease among HIV-infected women. J Infect Dis. 2012;205(12): 1788-1796.

104. Hechter RC, Budoff M, Hodis HN, et al. Herpes simplex virus type 2 (HSV-2) as a coronary atherosclerosis risk factor in HIV-infected men: multicenter AIDS cohort study. Atherosclerosis. 2012;223(2): 433-436.

105. Islam FM, Wu J, Jansson J, Wilson DP. Relative risk of renal disease among people living with HIV: a systematic review and meta-analysis. BMC Public Health. 2012;12:234.

106. Maggi P, Bartolozzi D, Bonfanti P, et al. Renal complications in HIV disease: between present and future. AIDS Rev. 2012;14(1):37-53.

107. Kalayjian RC, Franceschini N, Gupta SK, et al. Suppression of HIV-1 replication by antiretroviral therapy improves renal function in persons with low CD4 cell counts and chronic kidney disease. AIDS. 2008; 22(4):481-487.

108. Choi AI, Shlipak MG, Hunt PW, Martin JN, Deeks SG. HIV-infected persons continue to lose kidney function despite successful antiretroviral therapy. AIDS. 2009;23(16):2143-2149.

109. Kalayjian RC, Lau B, Mechekano RN, et al. Risk factors for chronic kidney disease in a large cohort of HIV-1 infected individuals initiating antiretroviral therapy in routine care. AIDS. 2012;26(15): 1907-1915.

110. Neuhaus J, Jacobs DR, Baker JV, et al. Markers of inflammation, coagulation, and renal function are elevated in adults with HIV infection. J Infect Dis. 2010;201(12):1788-1795. 
111. Calza L, Pocaterra D, Pavoni M, et al. Plasma levels of VCAM-1, ICAM-1, E-Selectin, and P-Selectin in 99 HIV-positive patients versus 51 HIV-negative healthy controls. J Acquir Immune Defic Syndr. 2009;50(4):430-432.

112. Melendez MM, McNurlan MA, Mynarcik DC, Khan S, Gelato MC. Endothelial adhesion molecules are associated with inflammation in subjects with HIV disease. Clin Infect Dis. 2008;46(5):775-780.

113. Hileman CO, Carman TL, Longenecker CT, et al. Rate and predictors of carotid artery intima media thickness progression in antiretroviralnaive HIV-infected and uninfected adults: a 48-week matched prospective cohort study. Antivir Ther. 2013;18(7):921-929.

114. Kurz K, Teerlink T, Sarcletti M, Weiss G, Zangerle R, Fuchs D. Plasma concentrations of the cardiovascular risk factor asymmetric dimethylarginine (ADMA) are increased in patients with HIV-1 infection and correlate with immune activation markers. Pharmacol Res. 2009;60(6):508-514.

115. Triant VA, Meigs JB, Grinspoon SK. Association of C-reactive protein and HIV infection with acute myocardial infarction. J Acquir Immune Defic Syndr. 2009;51(3):268-273.

116. Kuller LH, Tracy R, Belloso W, et al; INSIGHT SMART Study Group. Inflammatory and coagulation biomarkers and mortality in patients with HIV infection. PLoS Med. 2008;5(10):e203.

117. Duprez DA, Neuhaus J, Kuller LH, et al; INSIGHT SMART Study Group. Inflammation, coagulation and cardiovascular disease in HIVinfected individuals. PLoS One. 2012;7(9):e44454.

118. Nordell AD, McKenna M, Borges ÁH, Duprez D, Neuhaus J, Neaton JD; INSIGHT SMART, ESPRIT Study Groups; SILCAAT Scientific Committee. Severity of cardiovascular disease outcomes among patients with HIV is related to markers of inflammation and coagulation. J Am Heart Assoc. 2014;3(3):e000844.

119. Tenorio AR, Zheng Y, Bosch RJ, et al. Soluble markers of inflammation and coagulation but not T-cell activation predict non-AIDS-defining morbid events during suppressive antiretroviral treatment. J Infect Dis. 2014;210(8):1248-1259.

120. Longenecker CT, Funderburg NT, Jiang Y, et al. Markers of inflammation and CD8 T-cell activation, but not monocyte activation, are associated with subclinical carotid artery disease in HIV-infected individuals. HIV Med. 2013;14(6):385-390.

121. Ross AC, Rizk N, O'Riordan MA, et al. Relationship between inflammatory markers, endothelial activation markers, and carotid intimamedia thickness in HIV-infected patients receiving antiretroviral therapy. Clin Infect Dis. 2009;49(7):1119-1127.

122. Jang JJ, Berkheimer SB, Merchant M, Krishnaswami A. Asymmetric dimethylarginine and coronary artery calcium scores are increased in patients infected with human immunodeficiency virus. Atherosclerosis. 2011;217(2):514-517.

123. Burdo TH, Lentz MR, Autissier P, et al. Soluble CD163 made by monocyte/macrophages is a novel marker of HIV activity in early and chronic infection prior to and after anti-retroviral therapy. J Infect Dis. 2011;204(1):154-163.

124. Beltrán LM, Muñoz Hernández R, de Pablo Bernal RS, et al. Reduced sTWEAK and increased sCD163 levels in HIV-infected patients: modulation by antiretroviral treatment, HIV replication and HCV co-infection. PLoS One. 2014;9(3):e90541.

125. Burdo TH, Lo J, Abbara S, et al. Soluble CD163, a novel marker of activated macrophages, is elevated and associated with noncalcified coronary plaque in HIV-infected patients. J Infect Dis. 2011;204(8): 1227-1236.

126. Fitch KV, Srinivasa S, Abbara S, et al. Noncalcified coronary atherosclerotic plaque and immune activation in HIV-infected women. J Infect Dis. 2013;208(11):1737-1746.

127. Subramanian S, Tawakol A, Burdo TH, et al. Arterial inflammation in patients with HIV. JAMA. 2012;308(4):379-386.

128. Longenecker CT, Jiang Y, Orringer CE, et al. Soluble CD14 is independently associated with coronary calcification and extent of subclinical vascular disease in treated HIV infection. AIDS. 2014;28(7): 969-977.
129. Baker JV, Hullsiek KH, Singh A, et al; CDC SUN Study Investigators. Immunologic predictors of coronary artery calcium progression in a contemporary HIV cohort. AIDS. 2014;28(6):831-840.

130. Kristoffersen US, Kofoed K, Kronborg G, Giger AK, Kjaer A, Lebech AM. Reduction in circulating markers of endothelial dysfunction in HIV-infected patients during antiretroviral therapy. HIV Med. 2009;10(2):79-87.

131. McComsey GA, Kitch D, Daar ES, et al. Inflammation markers after randomization to abacavir/lamivudine or tenofovir/emtricitabine with efavirenz or atazanavir/ritonavir. AIDS. 2012;26(11):1371-1385.

132. Calmy A, Gayet-Ageron A, Montecucco F, et al; STACCATO Study Group. HIV increases markers of cardiovascular risk: results from a randomized, treatment interruption trial. AIDS. 2009;23(8): 929-939.

133. Wolf K, Tsakiris DA, Weber R, Erb P, Battegay M; Swiss HIV Cohort Study. Antiretroviral therapy reduces markers of endothelial and coagulation activation in patients infected with human immunodeficiency virus type 1. J Infect Dis. 2002;185(4):456-462.

134. Kurz K, Teerlink T, Sarcletti M, Weiss G, Zangerle R, Fuchs D. Asymmetric dimethylarginine concentrations decrease in patients with HIV infection under antiretroviral therapy. Antivir Ther. 2012;17(6):1021-1027.

135. Baker JV, Neuhaus J, Duprez D, et al; INSIGHT SMART Study Group. HIV replication, inflammation, and the effect of starting antiretroviral therapy on plasma asymmetric dimethylarginine, a novel marker of endothelial dysfunction. J Acquir Immune Defic Syndr. 2012;60(2): 128-134.

136. Jaworowski A, Ellery P, Maslin CL, et al. Normal CD16 expression and phagocytosis of Mycobacterium avium complex by monocytes from a current cohort of HIV-1-infected patients. J Infect Dis. 2006;193(5): 693-697.

137. Kamat A, Misra V, Cassol E, et al. A plasma biomarker signature of immune activation in HIV patients on antiretroviral therapy. PLoS One. 2012;7(2):e30881.

138. Malherbe G, Steel HC, Cassol S, et al. Circulating biomarkers of immune activation distinguish viral suppression from nonsuppression in HAART-treated patients with advanced HIV-1 subtype C infection. Mediators Inflamm. 2014;2014:198413.

139. Hatano H, Yukl SA, Ferre AL, et al. Prospective antiretroviral treatment of asymptomatic, HIV-1 infected controllers. PLoS Pathog. 2013;9(10):e1003691.

140. Hsue PY, Hunt PW, Schnell A, et al. Role of viral replication, antiretroviral therapy, and immunodeficiency in HIV-associated atherosclerosis. AIDS. 2009;23(9):1059-1067.

141. Pereyra F, Lo J, Triant VA, et al. Increased coronary atherosclerosis and immune activation in HIV-1 elite controllers. AIDS. 2012;26(18): 2409-2412.

142. Ho JE, Scherzer R, Hecht FM, et al. The association of CD4+ T-cell counts and cardiovascular risk in treated HIV disease. AIDS. 2012;26(9):1115-1120.

143. van Lelyveld SF, Gras L, Kesselring A, et al; ATHENA national observational cohort study. Long-term complications in patients with poor immunological recovery despite virological successful HAART in Dutch ATHENA cohort. AIDS. 2012;26(4):465-474.

144. Grant PM, Kitch D, McComsey GA, et al. Low baseline CD4+ count is associated with greater bone mineral density loss after antiretroviral therapy initiation. Clin Infect Dis. 2013;57(10):1483-1488.

145. Chevalier MF, Petitjean G, Dunyach-Rémy C, et al. The Th17/Treg ratio, IL-1RA and sCD14 levels in primary HIV infection predict the T-cell activation set point in the absence of systemic microbial translocation. PLoS Pathog. 2013;9(6):e1003453.

146. Vinikoor MJ, Cope A, Gay CL, et al. Antiretroviral therapy initiated during acute HIV infection fails to prevent persistent T-cell activation. J Acquir Immune Defic Syndr. 2013;62(5):505-508.

147. Jain V, Hartogensis W, Bacchetti P, et al. Antiretroviral therapy initiated within 6 months of HIV infection is associated with lower T-cell activation and smaller HIV reservoir size. J Infect Dis. 2013;208(8): 1202-1211. 
148. Wilkin TJ, Lalama CM, McKinnon J, et al. A pilot trial of adding maraviroc to suppressive antiretroviral therapy for suboptimal CD4+ T-cell recovery despite sustained virologic suppression: ACTG A5256. $J$ Infect Dis. 2012;206(4):534-542.

149. Hunt PW, Shulman NS, Hayes TL, et al. The immunologic effects of maraviroc intensification in treated HIV-infected individuals with incomplete CD4+ T-cell recovery: a randomized trial. Blood. 2013;121(23):4635-4646.

150. Massanella M, Negredo E, Puig J, et al. Raltegravir intensification shows differing effects on CD8 and CD4 T cells in HIV-infected HAART-suppressed individuals with poor CD4 T-cell recovery. AIDS. 2012;26(18):2285-2293.

151. Hatano H, Scherzer R, Wu Y, et al. A randomized controlled trial assessing the effects of raltegravir intensification on endothelial function in treated HIV infection. J Acquir Immune Defic Syndr. 2012;61(3):317-325.

152. Hatano H, Strain MC, Scherzer R, et al. Increase in 2-long terminal repeat circles and decrease in D-dimer after raltegravir intensification in patients with treated HIV infection: a randomized, placebocontrolled trial. J Infect Dis. 2013;208(9):1436-1442.

153. Silva EF, Charreau I, Gourmel B, et al; ANRS 138 EASIER Study Group. Decreases in inflammatory and coagulation biomarkers levels in HIV-infected patients switching from enfuvirtide to raltegravir: ANRS 138 substudy. J Infect Dis. 2013;208(6):892-897.

154. Martínez E, D'Albuquerque PM, Llibre JM, et al; SPIRAL Trial Group. Changes in cardiovascular biomarkers in HIV-infected patients switching from ritonavir-boosted protease inhibitors to raltegravir. AIDS. 2012;26(18):2315-2326.

155. Masiá M, Martínez E, Padilla S, Gatell JM, Gutiérrez F. Endothelial function in HIV-infected patients switching from a boosted protease inhibitor-based regimen to raltegravir: a substudy of the SPIRAL study. J Antimicrob Chemother. 2013;68(2):409-413.

156. Klatt NR, Funderburg NT, Brenchley JM. Microbial translocation, immune activation, and HIV disease. Trends Microbiol. 2013;21(1): 6-13.

157. Brenchley JM, Price DA, Schacker TW, et al. Microbial translocation is a cause of systemic immune activation in chronic HIV infection. Nat Med. 2006;12(12):1365-1371.

158. Wilson EM, Sereti I. Immune restoration after antiretroviral therapy: the pitfalls of hasty or incomplete repairs. Immunol Rev. 2013;254(1):343-354.

159. Mehandru S, Poles MA, Tenner-Racz K, et al. Primary HIV-1 infection is associated with preferential depletion of CD4+ T lymphocytes from effector sites in the gastrointestinal tract. $J$ Exp Med. 2004;200(6):761-770.

160. Mavigner M, Cazabat M, Dubois M, et al. Altered CD4+ T cell homing to the gut impairs mucosal immune reconstitution in treated HIV-infected individuals. J Clin Invest. 2012;122(1):62-69.

161. Legein B, Temmerman L, Biessen EA, Lutgens E. Inflammation and immune system interactions in atherosclerosis. Cell Mol Life Sci. 2013;70(20):3847-69.

162. Funderburg NT, Jiang Y, Debanne SM, et al. Rosuvastatin treatment reduces markers of monocyte activation in HIV-infected subjects on antiretroviral therapy. Clin Infect Dis. 2014;58(4):588-595.

163. Eckard AR, Jiang Y, Debanne SM, Funderburg NT, McComsey GA Effect of 24 weeks of statin therapy on systemic and vascular inflammation in HIV-infected subjects receiving antiretroviral therapy. J Infect Dis. 2014;209(8):1156-1164.

164. Ridker PM, Cushman M, Stampfer MJ, Tracy RP, Hennekens CH. Inflammation, aspirin, and the risk of cardiovascular disease in apparently healthy men. N Engl J Med. 1997;336(14):973-979.

165. Ridker PM, Hennekens CH, Buring JE, Rifai N. C-reactive protein and other markers of inflammation in the prediction of cardiovascular disease in women. $N$ Engl J Med. 2000;342(12):836-843.

166. Ridker PM, Buring JE, Cook NR, Rifai N. C-reactive protein, the metabolic syndrome, and risk of incident cardiovascular events: an 8-year follow-up of 14719 initially healthy American women. Circulation. 2003;107(3):391-397.
167. Ballantyne CM, Hoogeveen RC, Bang H, et al. Lipoprotein-associated phospholipase A2, high-sensitivity C-reactive protein, and risk for incident ischemic stroke in middle-aged men and women in the Atherosclerosis Risk in Communities (ARIC) study. Arch Intern Med. 2005;165(21):2479-2484.

168. Ford ES, Greenwald JH, Richterman AG, et al. Traditional risk factors and D-dimer predict incident cardiovascular disease events in chronic HIV infection. AIDS. 2010;24(10):1509-1517.

169. Cesari M, Penninx BW, Newman AB, et al. Inflammatory markers and cardiovascular disease (The Health, Aging and Body Composition [Health ABC] Study). Am J Cardiol. 2003;92(5):522-528.

170. Folsom AR, Chambless LE, Ballantyne CM, et al. An assessment of incremental coronary risk prediction using $\mathrm{C}$-reactive protein and other novel risk markers: the atherosclerosis risk in communities study. Arch Intern Med. 2006;166(13):1368-1373.

171. Tzoulaki I, Murray GD, Lee AJ, Rumley A, Lowe GD, Fowkes FG. Relative value of inflammatory, hemostatic, and rheological factors for incident myocardial infarction and stroke: the Edinburgh Artery Study. Circulation. 2007;115(16):2119-2127.

172. Danesh J, Kaptoge S, Mann AG, et al. Long-term interleukin-6 levels and subsequent risk of coronary heart disease: two new prospective studies and a systematic review. PLoS Med. 2008;5(4):e78.

173. Takei Y, Di Tullio MR, Homma S, et al. Soluble tumor necrosis factor receptor 1 level is associated with left ventricular hypertrophy: the northern Manhattan study. Am J Hypertens. 2009;22(7):763-769.

174. Valgimigli $M, C$ Ceconi $C$, Malagutti $P$, et al. Tumor necrosis factor-alpha receptor 1 is a major predictor of mortality and new-onset heart failure in patients with acute myocardial infarction: the Cytokine-Activation and Long-Term Prognosis in Myocardial Infarction (C-ALPHA) study. Circulation. 2005;111(7):863-870.

175. Ueland T, Kjekshus J, Frøland SS, et al. Plasma levels of soluble tumor necrosis factor receptor type I during the acute phase following complicated myocardial infarction predicts survival in high-risk patients. J Am Coll Cardiol. 2005;46(11):2018-2021.

176. Nilsson L, Szymanowski A, Swahn E, Jonasson L. Soluble TNF receptors are associated with infarct size and ventricular dysfunction in ST-elevation myocardial infarction. PLoS One. 2013;8(2): e55477.

177. Moreno JA, Muñoz-García B, Martín-Ventura JL, et al. The CD163expressing macrophages recognize and internalize TWEAK: potential consequences in atherosclerosis. Atherosclerosis. 2009;207(1): 103-110.

178. Aristoteli LP, Møller HJ, Bailey B, Moestrup SK, Kritharides L. The monocytic lineage specific soluble CD163 is a plasma marker of coronary atherosclerosis. Atherosclerosis. 2006;184(2):342-347.

179. Moreno JA, Dejouvencel T, Labreuche J, et al. Peripheral artery disease is associated with a high CD163/TWEAK plasma ratio. Arterioscler Thromb Vasc Biol. 2010;30(6):1253-1262.

180. Knudsen A, Møller HJ, Katzenstein TL, et al. Soluble CD163 does not predict first-time myocardial infarction in patients infected with human immunodeficiency virus: a nested case-control study. $B M C$ Infect Dis. 2013;13:230.

181. Reiner AP, Lange EM, Jenny NS, et al. Soluble CD14: genomewide association analysis and relationship to cardiovascular risk and mortality in older adults. Arterioscler Thromb Vasc Biol. 2013;33(1): $158-164$.

182. Kelesidis T, Kendall MA, Yang OO, Hodis HN, Currier JS. Biomarkers of microbial translocation and macrophage activation: association with progression of subclinical atherosclerosis in HIV-1 infection. $J$ Infect Dis. 2012;206(10):1558-1567.

183. Rogacev KS, Seiler S, Zawada AM, et al. CD14++CD16+ monocytes and cardiovascular outcome in patients with chronic kidney disease. Eur Heart J. 2011;32(1):84-92.

184. Rogacev KS, Cremers B, Zawada AM, et al. CD14++CD16+ monocytes independently predict cardiovascular events: a cohort study of 951 patients referred for elective coronary angiography. $\mathrm{J} \mathrm{Am} \mathrm{Coll}$ Cardiol. 2012;60(16):1512-1520. 
185. Heine GH, Ulrich C, Seibert E, et al. CD14(++)CD16+ monocytes but not total monocyte numbers predict cardiovascular events in dialysis patients. Kidney Int. 2008;73(5):622-629.

186. Jaipersad AS, Shantsila A, Lip GY, Shantsila E. Expression of monocyte subsets and angiogenic markers in relation to carotid plaque neovascularization in patients with pre-existing coronary artery disease and carotid stenosis. Ann Med. 2014;11:1-9.

187. Berg KE, Ljungcrantz I, Andersson L, et al. Elevated CD14++CD16monocytes predict cardiovascular events. Circ Cardiovasc Genet. 2012;5(1):122-131.

188. Barbour JD, Jalbert EC, Chow DC, et al. Reduced CD14 expression on classical monocytes and vascular endothelial adhesion markers independently associate with carotid artery intima media thickness in chronically HIV-1 infected adults on virologically suppressive anti-retroviral therapy. Atherosclerosis. 2014;232(1):52-58.

189. Hwang SJ, Ballantyne CM, Sharrett AR, et al. Circulating adhesion molecules VCAM-1, ICAM-1, and E-selectin in carotid atherosclerosis and incident coronary heart disease cases: the Atherosclerosis Risk In Communities (ARIC) study. Circulation. 1997;96(12): 4219-4225.

190. Blankenberg S, Rupprecht HJ, Bickel C, et al. Circulating cell adhesion molecules and death in patients with coronary artery disease. Circulation. 2001;104(12):1336-1342.

191. Hileman CO, Longenecker CT, Carman TL, McComsey GA. C-reactive protein predicts 96 -week carotid intima media thickness progression in HIV-infected adults naive to antiretroviral therapy. J Acquir Immune Defic Syndr. 2014;65(3):340-344.

192. Schnabel R, Blankenberg S, Lubos E, et al. Asymmetric dimethylarginine and the risk of cardiovascular events and death in patients with coronary artery disease: results from the AtheroGene Study. Circ Res. 2005;97(5):e53-e59.
193. Leong T, Zylberstein D, Graham I, et al; Swedish-Irish-Norwegian Collaboration. Asymmetric dimethylarginine independently predicts fatal and nonfatal myocardial infarction and stroke in women: 24-year follow-up of the population study of women in Gothenburg. Arterioscler Thromb Vasc Biol. 2008;28(5):961-967.

194. Parikh RV, Scherzer R, Nitta EM, et al. Increased levels of asymmetric dimethylarginine are associated with pulmonary arterial hypertension in HIV infection. AIDS. 2014;28(4):511-519.

195. Blanco-Colio LM, Martín-Ventura JL, Muñóz-García B, et al. Identification of soluble tumor necrosis factor-like weak inducer of apoptosis (sTWEAK) as a possible biomarker of subclinical atherosclerosis. Arterioscler Thromb Vasc Biol. 2007;27(4):916-922.

196. Jelić-Ivanović Z, Bujisić N, Spasić S, Bogavac-Stanojević N, Spasojević-Kalimanovska V, Kotur-Stevuljević J. Circulating sTWEAK improves the prediction of coronary artery disease. Clin Biochem. 2009;42(13-14):1381-1386.

197. Yilmaz MI, Sonmez A, Ortiz A, et al. Soluble TWEAK and PTX3 in nondialysis CKD patients: impact on endothelial dysfunction and cardiovascular outcomes. Clin J Am Soc Nephrol. 2011;6(4):785-792.

198. Chorianopoulos E, Rosenberg M, Zugck C, Wolf J, Katus HA, Frey N. Decreased soluble TWEAK levels predict an adverse prognosis in patients with chronic stable heart failure. Eur J Heart Fail. 2009;11(11):1050-1056.

199. Urbonaviciene G, Martin-Ventura JL, Lindholt JS, et al. Impact of soluble TWEAK and CD163/TWEAK ratio on long-term cardiovascular mortality in patients with peripheral arterial disease. Atherosclerosis. 2011;219(2):892-899.
Vascular Health and Risk Management

\section{Publish your work in this journal}

Vascular Health and Risk Management is an international, peerreviewed journal of therapeutics and risk management, focusing on concise rapid reporting of clinical studies on the processes involved in the maintenance of vascular health; the monitoring, prevention and treatment of vascular disease and its sequelae; and the involvement of

\section{Dovepress}

metabolic disorders, particularly diabetes. This journal is indexed on PubMed Central and MedLine. The manuscript management system is completely online and includes a very quick and fair peer-review system, which is all easy to use. Visit http://www.dovepress.com/ testimonials.php to read real quotes from published authors. 